\title{
Complexities in the Career-Family Perspectives of Young Professionals
}

\section{Tanya Castleman, Darryl Coulthard and Rosslyn Reed}

\begin{abstract}
Work-life balance issues are not a constant but are framed differently at different stages of the life-course. In addition to analysing behaviour, it is also important to develop an understanding of the meaning that actors attach to what they do. This article examines the perspectives of young Australian professionals on career, relationships and family formation as these evolve over the early years after university graduation. It provides an insight into their views about the balance between their career goals and family in the early years of their professional working lives. It reports a longitudinal study of 86 young A ustralian professionals from 1997 to 2003, which highlights the emergent and contingent nature of decisions about careers and relationships and their relevance for childbearing. Gender plays a role in their plans and expectations but they reject the traditional male breadwinner model. The high value given to dual career relationships may put stress on their ability to balance family aspirations with satisfactory careers.
\end{abstract}

\section{Introduction}

Over the past twenty years there has been an increasing recognition of the importance of reconciling the needs of private and family life with the needs of the workplace. This was originally framed as an issue of women's employment opportunity (Victorian Government 2005; Rapoport et al 2002), but it has come to be seen more broadly as connected to employee satisfaction and the ability to recruit and retain good employees in an increasingly competitive market for skilled and professional labour (DTI 2003; Macklin 2002).

The often competing demands of employment and family must be managed throughout one's working life, but the issues change depending on the stage in the lifecourse. In the early years plans for travel may take precedence, whereas late in the career elder care issues may predominate. Perhaps the most pressing issues of work-life balance are encountered around the birth of the first child when a major watershed occurs in family responsibilities (CRFR 2004: 3). This stage of the life-course raises work-family tensions most acutely and some people may respond by avoiding them or by delaying 
or not having children (Canold 2004). Such choices also have longer term demographic consequences (IGR 2002; McDonald 2001). The importance of work-life balance in this stage of the life-course can hardly be overemphasised (Goward 2005).

Underpinning developments over the life-course are longer-term social changes in behaviour and attitudes among successive age cohorts. It is not valid to assume that younger people, especially those now entering the prime family formation years, approach work and family issues and the balance between them in the same way that previous generations have. Later marriage, deferred childbearing and short-lived relationships (Weston and Parker 2002) can all be seen as indicators of change. There has been a good deal of comment in the popular press as well as the research literature about these trends (e.g., SMH 2005; Swan 2002; McDonald 2000b; Dempsey and De Vaus 2004, Withers 2004; Birrell, Rapson and Hourigan 2004). The world views and motivations behind the population figures are incompletely understood, which sometimes results in stereotyped characterisations such as allegations of selfishness among younger generations (Delli Carpini 2000).

This article examines the work-life balance issues encountered by Australian professionals during the stage of the life-course when they are establishing both their careers and long-term personal relationships and they are considering having children. The focus on a professional group highlights the salience of career considerations. These young professionals have made a heavy investment in education and career development. While they are privileged in that they have many opportunities for career advancement, their choices are circumscribed by the need to maintain continuity of professional employment, to keep their professional skills current and to preserve their networks of contacts.

The significance of career to both women and men is central to understanding work and life balance issues. The importance of career or work generally to men's identity is well established and generally unquestioned (e.g. Sennett 1998). Women's involvement with work and career has increased substantially over time and they now have a greater involvement in and commitment to education and careers. Using official statistics, Preston and Burgess (2003) have charted changes in Australian women's education and employment for the last decades of the twentieth century. Women are now a majority of tertiary education students and their participation in the labour force has increased dramatically since the 1960's (Preston and Burgess 2003:498-503). In line with their increasing educational attainment, women have also increased their participation in professional employment. Career is now central to many, if not most, professional women's identity, having invested heavily in education and successfully commenced a career. However, Preston and Burgess (2003: 510-513) note the lack of change in employment outcomes for women overall, which may suggest that there are risks to careers by breaks to have children.

A major issue for young adults is establishing a long term relationship (or, perhaps, developing a lifestyle in opposition to conventional relationships). Uhlman (2005), in his study of the 'stasis and inertia' of the modern Australian family, argues 
that despite many changes the conventional nuclear family remains the norm for most people. Uhlman refers to the work of McGregor (1997), who argues that the nuclear family remains an important part of the Australian dream:

... the middle class in Australia seems to have a persistent drawing power in terms of ethos, image and lifestyle. At its centre is the home, classically a bungalow with its own front garden and backyard in which the middle class lives, dreams, procreates, raises children and enacts a ritual of work/sleep/sex/love/kids/ family/death which is at the very heart of the Australian dream. (McGregor 1997: 141-142)

It is in this context that young people in heterosexual relationships with reasonably conventional views of the family and children negotiate their relationships and careers and contemplate having children.

Neverthless, relationships are less stable than those established by previous generations. The reasons include increased individualism and the rise of the pure relationship (Giddens 1992), the weakening of social relationships generally (eg Putnam 2000 ) and the pressures of economic 'reform' on the family (Pusey 2003). McDonald (2000a) and Weston and Parker (2002) suggest that the early relationships and cohabitations following leaving home are themselves extremely fragile. The experience of these fragile relationships increases the motivation for young women to be socially and financially independent (McDonald 2000a) and to invest in education and career rather than rely on uncertain long-term commitments. Greater gender equity and financial independence also increase the fragility of relationships, because both partners can financially, and in all likelihood emotionally, afford to leave an undesirable relationship.

That the nuclear family remains part of the Australian dream does not necessarily mean that the dynamics within the nuclear family or the pressures on the family have remained unchanged. Indeed there is evidence that there have been substantial changes within the nuclear family. McDonald (2000a) and Pusey (2003) have argued that Australia has moved away from a 'male breadwinner model' where the man 'protected and provided' and the women 'cared and reproduced' (McDonald 2000a: 5). There has been a shift towards a gender equity model in which there is no natural necessity for there to be a gender division of labour between income earning, household maintenance and caring and nurturing work:

The present generation of young women does not see this future in terms of the male breadwinner model of the family. Indeed most would not stake their future living standard on the assumption that they will be fully dependent on the earnings of a man. Likewise, many young men do not wish to be in a position where they are fully supporting a dependent wife. They see their own living standards being enhanced if their partner is also earning. (McDonald, 2000a: 5)

This is not to argue that gender differences have disappeared. Women's employment in Australia as elsewhere has continued to be disproportionately within the traditional female fields of clerical, sales and service occupations, with women attracting lower 
earnings than men and often working only in part-time and casual positions (Preston and Burgess, 2003: 510-513). There has been considerable controversy about why these gender differences persist. For example, Hakim $(1995 ; 1996 ; 2000)$ has argued that the poorer career outcomes of women can be explained in terms of their own choices and a lower level of career commitment than men. This view has been hotly contested (Bruegal 1996; Crompton and Harris, 1998 and Ginn et al, 1996). Crompton and Harris (1998), for example, have argued that the choices available to women have in fact been limited. This debate has led to the focus on women's choices and the ways in which their decisions about children and families have been gendered and constrained. It is clear that young women (and men) today confront major difficulties in combining children and a viable career (Gerson 2002; Probert 2002), which involves considerable conflict in the choices of educated women (Reed et al 2003).

Childbearing is a critical issue in women's careers. With the birth of children, women generally reduce their time and commitment to the workforce. On the other hand, men may actually increase their commitment to the workforce in response to becoming parents (CRFR 2004: 3). This pattern has implications for women's careers in the professional workplace and their influence within the family (Bittman 1993). Negotiating this period of their lives will have long-term implications. Many will delay having children or not have any children at all, outcomes that will be more likely if opportunities to balance career and family are not available (Canold 2004).

We should also note concerns about the rising costs of social reproduction (Pusey 2003; Uhlman 2005). The upbringing of children entails costs in terms of money, effort and energy as well as costs in salaries foregone and careers stalled or truncated. This issue is especially acute for women.

These factors contribute to what Uhlman (2005) identifies as a growing gap between the onset of adulthood and childbearing. Education, career investment, education debt (Jackson 2002) and debt overall (CPA 2004) widen that gap, which demographic analyses indicate as reducing the fertility of Australian women (eg McDonald 2000a; Quiggan 2001, Weston and Parker 2002). McDonald (2000a:1) reports that women are likely to restrict the number of children they have if having children limits their careers. The challenge many women face is how to successfully and realistically combine the goals of having children and pursuing careers. Men are not immune to these issues either. They are affected by their partners' aspirations and decisions. In contrast to the intense scrutiny of women's career and family issues, men's standpoints on career and family issues have been largely neglected.

In this paper we explore the lived experiences of a sample of young Australians, both men and women, as they negotiate the early stages of their careers and family. We examine their perspectives on career, as these intersect with their perspectives on relationships and marriage and having children. Planning and choice are important, as is contingency, in their approach to this important point in the life-course. Through an interpretive, longitudinal study we are able to observe over four years their changing views of work, career, family and personal goals and how they make decisions about this over time. 
In the sections below the following questions are addressed:

- What are the aspirations of the participants in terms of their careers and personal relationships, and how do those aspirations change over time?

- How do they plan to achieve their aspirations both in career and relationship terms?

- How do they make decisions about career, relationships and children and what shapes those decisions?

\section{Study Method}

The results reported here are derived from a longitudinal study of a group of university graduates who were enrolled as domestic students and subsequently graduated in the disciplines of engineering, business, social work and library studies from four (less than 25 years of age) Australian universities in 1996. The disciplines were selected to gain a cross-section of professional careers ranging from the traditionally male-dominated discipline of engineering to the female-dominated professions of librarianship and social work. Commerce or business, at least from the point of view of graduations was viewed as somewhat gender balanced (Castleman and Coulthard 1998).

The participant group was initially formed from those who, in the course of a mail survey organised through their university, responded positively to an invitation to participate in an in-depth semi-structured interview on their work and career. Of the three hundred and twenty nine (329) who returned questionaires, 36 percent (120) agreed to an interview. Initial interviews were completed with 106 graduates (32 percent) in 1997-8.

We conducted a second round of interviews during 2001-2. We were able to locate and interview 86 respondents, which represented 81 percent of those who participated in the first round of interviews. This group was fairly evenly balanced between men (44 percent) and women ( 56 percent). Only one person who was contacted for the second round declined to participate. These two rounds of interviews are the basis for the analysis presented here.

The first part of the interview covered current employment circumstances, as well as short-term and long-term career goals. In the second part of the interview, participants were asked about their current living arrangements and their domestic responsibilities. In addition to asking the participants about their family and personal goals, we asked them what they thought they were likely to be doing in five years time.

The interviews took a little over one hour on average, with some lasting up to an hour and a half. The interviews revealed much rich information about the participants' early experiences of professional employment and the development of their working lives. They explored participants' workplace experiences and the sources of advice and inspiration they received. The questions about family and domestic life came near the end of the interview. Some respondents gave very detailed and candid accounts of their view of marriage, children and sharing domestic tasks. Questions about family and personal plans were asked in the context of career and life planning, with the result 
that the answers tended to concentrate on the work-family nexus. This article provides a synchronic or cross-sectional analysis of the interviews (Thomson, Holland, McGrellis, Bell, Henderson and Sharpe, 2004). A diachronic analysis to systematically analyse the changes for individual participants over time will form part of further study.

The method of analysis taken by the study team was that four participating researchers read all transcripts, marked passages and identified initial themes. These themes were then discussed, and after each individual researcher trialled the themes on through a number of iterations a final set of themes were identified for coding (cf Kvale, 1996). Two members of the team then coded the transcripts in accordance with these themes, discussing and resolving differences of view so that a final set of themes and codings were produced. We have used quotations from the interviews in this article to illustrate and elaborate recurring themes in the responses.

As with almost all qualitative studies, we cannot claim generalisability and we do not claim that our sample of interviews is representative of all young Australians or even of all young professionals. We can in effect only report on how our participants were working through the complex set of issues to do with managing careers, forming and consolidating relationships and having children.

\section{Issues and themes in the interviews}

This section discusses the common themes and issues that emerged from the two rounds of interviews. The interviews must be read against the context of the evolving professional and personal lives of the participants. Both career circumstances and personal circumstances changed for most of them over the four years between the two interviews. Only a small number were married or living in established de facto relationships at the time of the first interview, although many others mentioned a steady boy/girlfriend or a fiancé(e). Over half still lived at home with their parents. A substantial group were in traineeships or working in part-time or insecure jobs, although they clearly identified themselves within a professional area related to their university course.

Four years later, two thirds had moved out of their parents' home and were living independently. Most of them were married or in established de facto relationships. Two had separated from their spouses. At this point, their careers had become established and they spoke with far more confidence and focus about their professional directions and the professions themselves. A few were considering new career areas, but their ideas were tied to their qualifications and experience. At the time of the first interviews none had children and specific plans for children were still some way off at the time of the second interview. Only two participants, both women, had a child when the second interviews were conducted.

The themes we identified in our analysis and which we discuss here include careers and personal identity, dual career relationships, gender dynamics, perspectives on children and parenting and the nature of planning for career and family. 


\section{Career, identity and commitment}

The participants in this study expected to continue and to advance in their professional practice and their careers. Very few questioned the desirability of being in a professional occupation and most expressed long-term commitment to a career. Most took a strategic orientation to their career; that is, they planned their actions to achieve particular career outcomes. This included changing employers, seeking international experience and gaining additional qualifications. They did not have rigid career plans but kept their options open. Even the few who voiced doubts about their chosen occupational path looked for new career-based changes (either within the field in which they had taken their degrees or in other areas) rather than non-professional employment or non-employment. Both the men and women described futures in which being professionally employed (or self-employed) was a central element. There were, at least at face value, no gender differences in their statements about career and professional commitment. Both men and women were committed to careers and wished their careers to continue and grow.

Career engagement was a central feature of personal identity. In response to our questions about what would constitute a good life, the participants gave a central role to their professional career. This was not necessarily in terms of conventionally recognised success but in terms of satisfaction in doing the job and in some cases making a social contribution through their work (such as environmental engineering or community development). The importance of professional involvement was often implied rather than articulated, so much did they take this for granted.

Job-related concerns voiced in the first set of interviews revolved around high workloads (the work-life balance issues were largely seen in terms of work-leisure) and lack of recognition in the workplace because of their age. Over the years between the first and second interviews, changes in perspective were mainly in terms of clarity and focus rather than career direction. By the second round, the participants had more specific ideas about what they were doing and how it related to longer-term career plans. Most had settled into full-time employment, and their initial concerns about long hours of work had abated, although most worked more than a 40-hour week. They had acclimatised to the professional work environment, had often gained recognition and promotion and evinced a greater feeling of confidence about their career.

While the interviewees were committed to continuing and advancing their careers, they did not express commitment to particular employers. Two thirds had changed employers between the two interviews and many expressed a willingness or a determination to change again if the job did not match their expectations or aspirations. Changes in locality were sometimes sought and, at other times, accepted. As a group, they were mobile with high expectations.

\section{Relationship dynamics: Two careers in the balance}

The interviews took place at a stage in the participants' lives when relationships were forming and consolidating. They were asked about their living circumstances and 
relationships, especially as these impinged on their career plans and work performance. The relationships they described were often tentative, that is, they did not necessarily believe that they would be long term. This was typically expressed in the context of what job moves they might make and where they might move, especially in the first round of interviews. During the interviews, they responded to our questions about long-term plans in the first person whether or not they were currently in a relationship. The expressed long-term plans were about themselves, singly, not as a couple, and this caused some unease or reticence in the interview. They expressed a 'wait and see' attitude towards these relationships.

Their comments provide an insight into the fragility of relationships described by Weston and Parker (2002). Their expectations at this early stage incorporated the tentative and thus fragile nature of those relationships and in many cases indicated the centrality of career to their identities and plans. In the first round, one woman talked about her relationship with her boyfriend with whom she did not live:

We both work out where each other's priorities lie... he is aware where I'm at with my career and that I'm not prepared to give up much. [What we will do in the future] really depends on where we're at.

By the second round she was living with a different partner, anticipating marriage and moving to another locality to facilitate his career, without abandoning her own, though she had begun to think about that more flexibly as a result of her relationship. A few months after the interview was conducted she emailed the project team to advise that she had married and was moving interstate.

We can see the paradox that while partners are pivotal in life planning, in the early years these relationships are emergent and far less able to be conventionally planned. By the second round of interviews, personal relationships had become increasingly influential in career decisions, a pattern far less common in the first round when very few were partnered and even fewer were married.

Both men and women assumed that career and family arrangements would incorporate both partners' careers. This was reflected in the way they incorporated statements about their partners' careers in accounts of their thinking about their own career moves. In some cases they were quite explicit about how they made career plans with their partners or prospective spouses, and in nearly all cases, these were two professional careers. Many were explicit about their rejection of the traditional 'wife at home' family, but even those with conventional aspirations and a strong emphasis on family included dual career considerations in their responses. This approach is demonstrated in the following extract from a second round interview with a male engineer. It also shows the development of career and family perspectives over time:

The last time I spoke to you I would have said wherever I wanted to go; I would have had no ties basically. Now there's a second party that's got to be considered and as important as what the first party is. ... I would not move to a place just for a job, I would move to a place that was suited to us. 
In a few cases, priority was given to the woman's career - as described either by a female participant or a male participant talking about his partner. This did not indicate that the male partners had relinquished their own career aspirations but rather that, in seeking an accommodation, they had acted flexibly to meet their partners' career requirements. Sometimes this meant changing locations, as described by a female engineer, moving overseas to a new job:

I'm kind of lucky... I don't really want to compromise right now but I don't have to because [my boyfriend and ] both want the same things... He said to me to take a job wherever I find one because I have the specialist skills but he's got more general skills and could probably work in every major city. So he said to find work wherever I want then he'll find it around me.

In another case, a male respondent spoke of adjusting his own plans to his wife's professional career, while underlining that this did not mean he was less committed to his own aspirations:

Her career is as important as mine and her career definitely wouldn't take a back seat to mine or vice versa. But that being said, she's got more responsibility and is remunerated the highest overall...She is in a position where her career (I don't use the word more important) is perhaps higher than what mine is at the moment... One really has to consider the other person essentially as an equal partner.

In many cases satisfactory arrangements could be made, but career incompatibility was also a source of conflict. Several respondents described difficulties, mainly involving issues of where jobs were located. Some described the difficulties of maintaining longdistance relationships, and several spoke of major problems created by incompatible career requirements. For example, a female engineer reported the difficulties that she and her husband, also an engineer, experienced in trying to manage both careers in a profession which rewarded international experience:

I guess that sometimes [developments in my career] have made it hard... You realise it's not as easy as you thought it would be, you could always juggle it and be fair to each partner...It's not something that you can always do. I guess that was a shock to me.

Another participant had relocated because of his relationship with his girlfriend, who had a 'booming' professional practice. But his career had suffered as a consequence, which was in turn negatively affecting the relationship:

It really isn't ideal and I mean she knows and I've discussed it with her that I'm genuinely deeply unhappy with my work situation and that has such an effect ... We'll either work it out together and we would have kids or something by that stage, or I'll finally get to the stage where I just can't stand this any longer and be back [working at a job I'm really interested in. This is] certainly not really where I saw myself two or three years ago.

There was no suggestion in his account that either he or his partner thought that abandoning a career was an option. It is clear that both the men and women recognise the importance 
of career aspirations and work for their partners. How these expectations of dual careers and the equality of men's and women's careers play out in the future will be interesting. However, it is important that at this time they express the wish to work things out more or less equally.

\section{The influence of gender}

The similarities between men and women in their approaches to career outweighed the differences, at least as they spoke about their plans and aspirations. The rhetoric of gender equality was frequently expressed by both male and female respondents. Few women said that gender was an issue for them at work and many were assertive about the importance of their careers. The gender issues are more subtle, less commonly spoken about, yet sometimes detectable in what was unspoken or tacked on to statements that were otherwise egalitarian, such as the explanation by one man about the importance placed on his own and his wife's careers:

[M] career determines our lifestyle, just because of the amount of money I earn compared to my wife. But her job is as important to her as mine is to me. We would try to move to an area where she could transfer ... but if the job was the best job that it could be there, then at the end of the day she would give up her career for mine to prosper.

The women were protective of their equal status and determined to maintain their identities as professional women, but even so there were signs that the dual career ideal might have some vulnerabilities, especially with the advent of children. Reminiscent of the statement quoted above, the woman quoted below rather cedes the primary career role to her husband, while staunchly defending her professional identity:

The last thing I want is for my husband to think I' $m$ just a housewife... He and I have both been very equal, we both understand exactly what it's like to go to work ... We're going to take a bit of joint care of the maternity thing. So he'll be taking three months paternity. And then once the maternity or paternity leave is over... we'll need to decide which one of us becomes more 9 to 5 ... and it will probably be me, because 1 don't want to go as far as he does.

The rationales in these statements are different (earning power vs career drive), but they both have the effect of prioritising the male career, in part as a way of dealing with work and family issues. While the rhetoric of gender equality was almost universally endorsed, the undertones suggest continuing gender dynamics that are likely to create divergences in the outcomes for men and women.

There is a dominating discourse of gender equity, both as a value and as a description of experience. Only a few participants even raised the issue, most implying obliquely that gender issues are (now) unproblematic. This does not of course mean that this is so. Rather it indicates a lack of awareness of embedded gender processes and their long term impact on career and family outcomes. What we see are small differences between men and women that may become more significant when in the future they 
experience the pressures of having a family and maintaining a career. It would seem that it is not 'choice' or 'lack of career orientation' that is driving these differences (Hakim 1996) but choice within a particular set of circumstances. We anticipate that one consequence of the participants having children will be that gender disparities will emerge more starkly.

\section{Expectations of children and parenting}

Only two respondents had children at the time of the second interviews, but by that time some of the others were beginning to anticipate childbearing. As noted above, the development of stable relationships and marriages made this issue relevant in a way it had not been before. This shift of perspective occurred for both men and women.

Plans for children were generally forged in the context of relationship commitment, a pattern clearly detected during the second interviews. Those who were single articulated no plans for children, in line with their 'wait and see attitude towards relationships', whereas half of married respondents thought they would have children in the foreseeable future and most others spoke of having children in the more distant future. Women were more likely than men to say they planned to have children at some stage, a pattern not explained by their marital status. This may reflect a traditional assumption that women are more responsible for the decision to have children (or not). Or it may simply indicate the greater significance that having children still holds for women, as expressed somewhat ruefully by one of the women:

It is because being femaie you are expected to have children and you will take time out of your career, and to me, although that is important, I don't see why that should affect me now when I don't have children; I guess my husband doesn't necessarily agree with me.

Many were explicit about the impact that parenthood would have on their careers, but most had not grappled with the specifics of this. One woman voiced her uncertainty about both the desirability of having children and the implications this would have for her career:

I have this big dilemma with having kids. I'm not sure if I want them is the first thing. And if I do, I know they are going to interrupt my career terribly...Obviously children and the work has to continue. I find that a really big step to take, trying to incorporate children into my life at this stage.

For the women, the decision to have a child is considerably more fraught than for men and usually articulated in terms of career-family incompatibilities. There is no inexorable progression toward childbearing; instead there is a continuing tension that may change as circumstances in working life change. This tension is illustrated by the following quote. The woman has changed her mind a number of times as career opportunities arose:

I would have [had a baby] because my job wasn't as satisfying as I had hoped which is a bit of a cop out... Now that it's turned full circle, it's hard to believe I thought of leaving and I'm having a ball and I think I would rather stick at this a while longer and give it a 
lot more time. So it's gone full circle again. I think I've changed my mind so many times about when I thought I would like to have children....

It is almost impossible to imagine a male respondent describing his thoughts about having children in these terms. Gender would appear to operate such that men are much less aware of these tensions than women, for whom a family focus is a socially-accepted alternative if they experience difficulties in their careers.

\section{Planning horizons}

Most participants expressed a fairly clear sense of where they would like to be in career terms at both interviews, but most were also open to considering new opportunities which offered to them by their current employer, alternative job openings and prospects for travel. Discussing plans or goals for the future was far more difficult. When we asked the question' What changes do you think will happen in your home or life in the next five years?', quite a number found it difficult to articulate this at all, especially if they were not already partnered, as the interchange below between the interviewer and a single male participant illustrates:

[What changes do you think will happen in your home or life in the next five years?]

I'd like to, to settle down, probably start a family in that time. But yeah, who knows?

[So if you did settle down, how would it affect your career?]

Um, there would be a need to earn higher income, but also to, to sort of work shorter hours, um, which is a bit of a ..er conflict. Um, so that we could spend sort of time with, you know with my spouse and family, mmmh. ...

[And what are the main things you would like to happen in your career and family life in the next five years?]

Um...Other than the things I've said, I don't, don't know if there's any more. ... that's one of those sort of ad hoc things, just take it as it comes.

On the other hand, for participants in relationships a common source of contingency in their planning was the influence of partners' or spouses' job requirements or other changes in their relationship. They found the complexities of dealing with two careers, travel possibilities and other issues led to uncertainty or ambivalence.

Contrary to the popular view that young people, especially men, are reluctant to commit themselves to relationships (Mackay 2001), the majority of our participants spoke positively about this aspect of their lives - either in actuality or in prospect. Most incorporated marriage and partners into their description of a satisfying life in the far future, but until a particular relationship was established this aspect of their lives had little substance. They expected relationships and careers to be 'co-determined' with their partner. Until they had a partner they simply had a general, abstract goal that requires a partner in order to develop.

While all goals and plans remained fluid and subject to contingency, careers at this stage had more structure and purpose. In contrast, life goals were generally vague and more 
dependent upon matching and meshing with partners or other relationships. Life goals were broader and hence surrounded with greater complexity resulting in a more abstract picture.

At the time of the first interviews, family formation issues, though important to some, were usually seen by the participants as a part of later life goals. More than half still lived with their parents. Relationships were tentative and referred to less directly in interviews. Career goals and the options for travel were more immediate and could be the object of concrete plans. By the time of the second interviews, professional employment practices had become familiar. Some had travelled (with mixed career and personal outcomes), and relationships were adding complexity to decision making concerning careers, travel, setting up households and having children.

When questioned directly in the first round of interviews about the arrangements in their workplaces for employees with family responsibilities, the majority said they thought these arrangements were satisfactory. But almost no-one had found occasion to delve into the specifics of these arrangements, undoubtedly because they didn't see it as relevant to them at that time. Their confidence may have been justified in some cases. The two participants (both women engineers) who had children by the time of the second round of interviews worked in organisations that had attempted to accommodate their new role as mothers. While many of the participants spoke of career advice received from mentors, peers, professional publications and even family, they did not identify exemplars who had successfully managed to combine career and family demands. References to those who were attempting to manage career and family demands were either negative (the demands it put on the workgroup) or admiring of something extraordinary and difficult to achieve ('I don't know how she does it'), evidence of their sense of distance from these issues.

Among those who did address themselves to work-family arrangements, many indicated an explicit or implied preference for parental care for children. When non-family childcare was mentioned, it was a negative reference. To the extent that a view of future childcare arrangements emerged, it involved either joint care by parents or a role borne by one partner - usually, but not always, by the mother. Many referred to periods out of the labour force for one or both partners, which was frequently accompanied by expressions of ambivalence, as expressed by the woman who said:

[m] I' $m$ going to have a family, the career would have to be on hold for at least 5 years until they're school aged and perhaps longer than that. I would like to [be home when children arrive from school] though whether that would drive me batty I don't know.

Only a few women had attempted to manage their careers such that the demands and conditions of the workplace were considered in both the plan to have children and the plan to care for them after they arrived. No man stated that he managed his career towards this end. Decisions, or even detailed consideration, about this aspect of their family and working lives appeared to be deferred until they had had children. Only 10 percent at the first interview and about 20 percent at the second interview described with any 
clarity how they might manage the combination of family and career. Only rarely did anyone report any guidance from supervisors or others in their workplace, or even that this issue was raised.

One woman who had made such plans was in a long-term relationship and had developed a business career. She was outspoken about how she valued her career and had worked out a plan in detail to have two children and resume her professional employment:

I'd like to give myself another 5 years [of working]... and have the sort of position in my company when you can go away for 2 or 3 years and then come back in a part-time capacity. ... So 1 think in 5 years it will be the perfect time for me to ... start a family... That still gives me time to have a young family and back to work in my late thirties... I think parttime first.

She continued to supply even greater detail about these plans, a rare example of concrete planning. Unusually, she cited the case of a more senior colleague who had successfully followed a similar plan.

Perhaps as a result of the difficulty of including childbearing in employment planning as well as the absence of planning until relationships had stabilised, several participants spoke of delaying having children, as not 'being ready'. The comments of a woman running her own business highlighted considerations other than work and family, including leisure and self-fulfilment:

Oh deary me, touchy subject! My partner wants a thousand children, and my idea is that I've done the hard slog putting in the commitment time to a business and I'm actually looking forward to free time. So I don't think I could ever live without children, but at the moment the longer I own this business the longer I' $m$ going to need to actually get the whole freedom and no responsibility thing out of my system I think. ...I don't want children at the moment ... it's not going to be in the next five years, absolutely not. In terms of having children, I'll still be young.

In fact there were many comments about the appropriate timing of children, with people trying to identify a right time that wasn't too early to interfere with career and personal plans but not so delayed as to be an 'old mother'.

Reflecting Uhlman's (2005) analysis, most respondents wanted a satisfying family life and in fairly conventional terms. Children were part of this picture but so was career, both as a material support for the desired lifestyle and as a source of satisfaction in its own right. The ability to travel was also important. The issues of work-life balance in the early years will become work-family issues, especially for the women, as they move into this stage of their lives, and easy solutions are unlikely to be found. They will encounter challenges, especially in partnerships with two professional careers, given the major mismatch between most Australian employment practices and ideal employmen practices which are truly 'family friendly' (McDonald 2001). 


\section{Choice, constraint and contingency in work-life decisions}

Returning to the questions posed at the outset of this paper, we look at what the interviews tell us about professionals' perspectives on family and career in the early career stages.

\section{What are the participants' aspirations for careers and personal relationships and how do those aspirations change over time?}

Aspirations for career success were linked with a sense of participation in a professional group. Career redirection was envisaged by some, but this was typically a variation of the profession for which they had trained. Most express a readiness to change employers to achieve success. In the early stages, these aspirations were fluid and they sought experience before deciding on direction. The transition from student life to full-time professional work entailed some adjustment, but this was not experienced as discouragement from the chosen career. More likely, an employer or workplace was seen as the cause of a problem. With greater experience, the respondents became more confident and specific about their career direction, and for the majority these were consistent with their original aspirations.

In contrast to the confident rational, calculable world of the workplace, statements of what they wanted from relationships and having children were tentative and imprecise, at least until an actual relationship was reasonably well established. Most articulated the desirability in the long term of establishing a partnership and family. But this ideal for many had no real substance until the partner could be visualised, and that depended on establishing the relationship. As a relationship became well-established, aspirations to travel, to buy a house, to get married, and to have children became more concrete. In the realm of the personal, experience overwhelmingly shapes aspirations or rather creates specific aspirations from inchoate orientations. Their aspirations for children were arguably the most tenuous of all major personal goals. They expressed significant ambivalence about the limitations that having children would involve. Many of these were career-related limitations, but there were life-style issues as well.

At the early stage of their professional lives, career aspirations were central in their thinking about what they wanted from life. Most of their comments focused on work issues. Relationships moderated and, in some cases, substantially altered these aspirations, but the professional orientation remained an important component of identity and an important component of their imagined futures.

How do the participants plan to achieve their aspirations both in career and relationship terms?

Against this background, planning took on a dual character. There are specific steps that can be taken to advance careers, such as gaining additional qualifications, applying for promotion, changing employers or negotiating changes of job tasks. As the participants were moderately strategic in their approach to career development, most regularly accessed 
advice from their employers, professional associations, networks and printed materials. Planning in personal terms, on the other hand, was tentative and diffuse. It was rare to hear a well-articulated plan for achieving career and family goals. A counterpoint to their expressed interest in establishing families and having children in the long term was their ambivalence about having children in the near future. This was most frequently articulated by women, for whom the issue had greater salience and a potentially greater impact because of the association, biological and social, of women with childbirth and childcare.

There is little evidence that the participants seriously considered the prospect of career-family tension before they establisheded long-term partnerships. When they did so, the issues became more concrete for them, but they engaged in little direct planning. Most assumed that their workplaces would accommodate them, and their faith may be, in many cases, well placed. But they had not seriously investigated their options nor had they considered how the arrangements might play out in practice. The contradictions between their career aspirations and their ideas about caring for children were not acknowledged.

The two aspects of planning, career and family, were asymmetrical. Career and work were rationally planned. The factors considered ranged from remuneration and promotion opportunities through to the climate of the workplace and the location of jobs. Personal milestones, such as cohabitation, engagement, marriage and childbearing might be planned for, but only once relationships had been consolidated. The lack of planning in this area is not a failing but an intrinsic characteristic of relationships. Childbearing plans began to firm once a relationship is defined, often by engagement or marriage, but their views were often ambivalent, in part because their focus was on the workplace, career development and financial considerations.

\section{How do they make decisions about career, relationships and children and what} shapes those decisions?

The respondents who were not in relationships made decisions about their careers unencumbered by partners, children or indeed any work-family issues. For those in established relationships, the process of decision-making about combining career, relationship and children was described as involving both partners in an egalitarian, unconstrained, rational exchange. Egalitarianism is a strongly-held value. It is reflected in the value placed on the careers of partners as well as their own careers. As no interviews were held with the partners of the respondents, we have no way of knowing to what extent this consensual, egalitarian picture of relationships represents their views. Undoubtedly the interviewees did not articulate all sources of conflict, tension and unequal power in the joint decision-making. The extent to which such relationships were egalitarian, particularly under social and work pressure, will undoubtedly be tested for our respondents in the future.

In the early career years and prior to having children, the participants were usually able to accommodate the dual career demands. The most commonly cited 
decision problem was which job to favour in decisions about where to live. When giving preference to one career, it was usually expressed in terms of career opportunities, not that one was more important than the other. Where a decision of this type was made, the male partner's career was more commonly but not always favoured.

Decision-making about children was mainly deferred, as none of the participants had deliberately embarked on childbearing at this stage. Their positive anticipation of having children in the long-term did not preclude their ambivalence in the shorter term. Ambivalence about when to begin this phase of their lives was more likely to be articulated by women - an indication that they expect to be affected more than their partner. They often spoke of having children as a distraction from satisfying career activities. This was despite avowals that their careers were of equal importance and that their partners would be centrally, if not equally, involved with caring for children. The men expressed less tension than the women about the decision to begin a family, implying that this would affect their working lives to a lesser degree. Their desire to be involved in the care and upbringing of their children and the value they placed on their partners' careers was not reflected in concern about how work-family issues would impinge on them.

The young professionals who participated in this study were highly motivated to pursue their careers, and as they progress they are likely to have more opportunities to move up, to travel and to take on additional responsibilities. While they recognised that careers are subject to life's vicissitudes, their own careers have a certain momentum and certainty. Moreover, they have supervisors, career development programs and their educational experience to encourage them to identify and pursue the next career step. The tenuous and contingent world of relationships and planning a family contrasts to the immediacy and concreteness of careers. While it is clear that most wanted careers as well as a family, they cited few examples of the successful balance of family and career among their peers and colleagues. In this respect, they were moving into largely uncharted territory.

The participants were beginning to confront a critical period in the life-course, as they weighed up career aspirations and personal and family goals. Those who are more ambitious about career will find that the demands do not slacken once they have established their careers. The career vs family equation is complicated by ongoing financial pressures to pay debts for study and, especially, to buy a house. Some will face the cost of further study to gain higher level professional and managerial positions. Nearly half expressed a wish to travel as well. All of these pressures will contribute to delayed childbearing.

The importance of managing both partners' careers puts stresses on couples. The anticipated strategies for incorporating children in the medium term attempt to protect both careers. This was seen as important for personal fulfilment and essential in the event that the marriage itself ends in divorce. Given the strong value they placed on both careers, they will not happily sacrifice either career to have children.

While many will undoubtedly negotiate these challenges with panache, others may face one or more unpalatable alternatives. Postponing childbearing for career reasons will almost certainly reduce fertility and for some will result in unwelcome childlessness. 
For others, especially women, having children and leaving the job to look after children in their early years will probably have a negative impact on career contribution and a substantial loss of their skills from the workforce. There is no guarantee that they will be able to pick up their careers where they left off if they exit the workforce. A couple determined to achieve satisfying family and professional lives are likely to find the burden of these goals is very heavy, given the demands of keeping up in workplaces hungry for long hours and a mobile workforce. Only imaginative, flexible and informed workplace arrangements for work-life balance will allow them to achieve both goals.

\section{References}

Birrell, R, Rapson, V and Hourigan, C. (2004) Men + Women Apart: Partnering in Australia, The Australian Family Association and Centre for Population and Urban Research, Monash University, Melbourne.

Bittman, M. and Lovejoy, F. (1993) 'Domestic power: Negotiating an unequal division of labour within a framework of equality' Australian and New Zealand Journal of Sociology, 29(3): 302-321.

Bruegal, I. (1996) 'Whose Myths are They Anyway? A comment' British Journal of Sociology, 47: 175-77.

Canold, L. (2004) 'Declining marriage rates and gender inequity in social institutions: Towards an adequately complex explanation for childlessness' People and Place, 12(4): 1-11.

Castleman, T. and Coulthard, D. (1998) Career Experiences of Young Australian Graduates: $A$ Preliminary Report on Survey Data, Institute of Social Research, Swinburne University of Technology.

CPA Australia. (2004). Research report: Debt and the ' $X$ ' and ' $Y$ ' Generation. Melbourne: CPA Australia.

CRFR (Centre for research on families and relationships) (2005) 'Work-life balance across the lifecourse', Research Briefing 21, March, 2005. http:/www.crfr.ac.uk/Reports/rb21.pdf Accessed 15/10/05

Crompton, R. and Harris, F. (1998) 'Explaining Women's Employment Patterns' British Journal of Sociology, 49: 118-36.

Delli Carpini, MX. (2000) 'Gen.com: Youth, Civic Engagement, and the New Information Environment' Political Communication, 17(4): 341-349.

Dempsey, $\mathrm{K}$ and De Vaus, D. (2004) 'Who cohabits in 2001?' Journal of Sociology, 40(2): $157-$ 178.

DTI (Department of Trade and Industry) (2003) Balancing work and family life: enhancing choice and support for parents, London http://www.dti.gov.uk/er/individual/balancing.pdf Accessed $15 / 10 / 05$.

Gerson, K. (2002) 'Moral Dilemmas, Moral Strategies, and the Transformation of Gender: Lessons from Two Generations of Work and Family Change' Gender \& Society, 16: 8-28.

Giddens, A. (1992) The transformation of intimacy: Sexuality, love, and eroticism in modern societies, Stanford, Calif, Stanford University Press. 
Ginn, J., Arber, S., Brannen, J., Dale, A., Dex, S., Elias, P., Moss, P., Pahl, J., Roberts, C. and Rubery, J. (1996) 'Feminist fallacies: A reply to Hakim on women's employment' British Journal of Sociology, 47(1):167-174.

Goward, P. (2005) 'After the barbeque: women, men, work and family', Australian Human Rights and Equal Opportunity Commission, 10/02/05 http://www,hreoc.gov.au/speeches/ sex_discrim/aifs Accessed 15/10/05.

Hakim, C. (1995) 'Five Feminist Myths about Women's Employment' British Journal of Sociology, 46: 429-55.

Hakim, C. (1996) 'The Sexual Division of Labour and Women's Heterogeneity' British Journal of Sociology, 47:178-88.

Hakim, C. (2000) Work-lifestyle Choices in the 21st Century, Oxford, Oxford University Press.

IGR (2002) (Intergenerational Report). Circulated by The Honourable Peter Costello, M.P., Treasurer of the Commonwealth of Australia, for the information of Honourable Members On the occasion of the budget 2002-03 14 May 2002. Canberra: Commonwealth of Australia.

Jackson, N. (2002) 'The higher education contribution scheme a HECS on the family'? Journal of Population Research, Special Issue, September: 105-119.

Kvale, S. (1996) Interviews: An introduction to qualitative research interviewing. Thousand Oaks, Sage.

McDonald, P. (2000a) 'Gender equity, social institutions and the future of fertility' Journal of Population Research, 17(1):1-16.

McDonald, P. (2000b) 'Low fertility in Australia: Evidence, causes and policy responses' People and Place, 8(2): 6-21.

McDonald, P. (2001) 'Work-family policies are the right approach to the prevention of very low fertility' People and Place, 9(3): 17-27.

McGregor, C. (1997) Class in Australia, Ringwood, Penguin Australia.

Mackay, H. (2001) 'The Free Generation' The Age, 19/08/01. http://www.theage.com.au/news/ state/2001/08/19/FFX9MEAAIOC.html, Netscape, 22/8/01)

Macklin, H. (2002) 'Balancing Work And Family And Staying Competitive', ACTU, Newsroom. http://www.actu.asn.au/public/news/1022648050 12007.html Accessed 15/10/05.

Preston, A. and Burgess, J. (2003) 'Women's Work in Australia: Trends, Issues and Prospects' Australian Journal of Labour Economics, 6(4): 497-518.

Probert, B. (2002) 'Grateful Slaves or Self-made Women: AMatter of Choice or Policy?' Australian Feminist Studies, 17: 7-17.

Pusey, M. (2003) The experience of middle Australia: The dark side of economic reform, Cambridge, Cambridge University Press.

Putnam, RD. (2000) Bowling alone: The collapse and revival of American community, New York, Simon \& Schuster.

Quiggan J. (2001) 'Demography and the new economy' Journal of Population Research 18: 177-93.

Rapoport, R., Bailyn, L., Fletcher, J. and Pruitt, B. (2002) Beyond Work-Family Balance: Advancing Gender Equity and Workplace Performance, San Francisco, Jossey-Bass.

Reed, R., Allen, M., Castleman, T and Coulthard, D. (2003) 'I mean, you want to be there for them: 
Young Australian professionais negotiating careers in a gendered world' Australian Journal of Labour Economics, 6: 519-36.

Sennett, R. (1998) The corrasion of character: The personal consequences of work in the new capitalism, New York, Norton.

Swan, W. (2002) 'Families: the sinking middle', On Line opinion-Australia's e-journal of social and political debate (posted Friday, Nov 8, 2002) http://www,onlineopinion.com.au/view. asp?article=1699 accessed 27 June 2005.

Sydney Morning Herald (2005) 'Where have all the babies gone?', 9 April 2005 http://www,smh com.au/news/Nationa/Where-have-all-the-babies-gone? accessed: 27 June 2005

Thomson, R., Holland, J., McGrellis, S., Bell, R., Henderson, S. and Sharpe, S. (2004) 'Inventing adulthoods: a biographical approach to understanding youth citizenship' Sociological Review 52: 218-39.

Uhlmann, AJ. (2005) 'The dynamics of stasis: Historical inertia in the evolution of the Australian family' The Australian Journal of Anthropology 16(1), pp. 31-36

Victorian Government (2002) Valuing Parenthood Options for Paid Maternity Leave: Interim Paper, Victorian Government Submission to the Human Rights Commission.

Weston, R and Parker, RA. (2002) 'Why is the fertility rate falling? A discussion of the literature' Family Matters 63: 6-13.

Withers, G. (2004) Australia's Population Future: A position paper, Prepared for the Business Council of Australia, http://www.bca.com.au/upload/Web.pdf accessed 27 June 2005.

TANYA CASTLEMAN - Deakin University, DARRYL COULTHARD -

Deakin University; ROSSLYN REED - University of Technology Sydney 